Article

\title{
Determination of Fracture Initiation Locations during Cross-Measure Drilling for Hydraulic Fracturing of Coal Seams
}

\author{
Yiyu Lu ${ }^{1,2}$, Yugang Cheng ${ }^{1,2, *}$, Zhaolong Ge ${ }^{1,2, *}$, Liang Cheng ${ }^{1,2}$, Shaojie Zuo ${ }^{1,2}$ \\ and Jianyu Zhong ${ }^{1,2}$ \\ 1 State Key Laboratory of Coal Mine Disaster Dynamics and Control, Chongqing University, \\ Chongqing 400044, China; luyiyu@cqu.edu.cn (Y.L.); chengliang@cqu.edu.cn (L.C.); \\ 20142002027@cqu.edu.cn (S.Z.); 20152002005t@cqu.edu.cn (J.Z.) \\ 2 National \& Local Joint Engineering Laboratory of Gas Drainage in Complex Coal Seam, \\ Chongqing University, Chongqing 400044, China \\ * Correspondence: chengyugang@cqu.edu.cn (Y.C.); gezhaolong@cqu.edu.cn (Z.G.); \\ Tel./Fax: +86-23-6510-6640 (Y.C. \& Z.G.)
}

Academic Editor: Vasily Novozhilov

Received: 29 March 2016; Accepted: 4 May 2016; Published: 11 May 2016

\begin{abstract}
When drilling coal-bearing sequences to enhance coal seam permeability by hydraulic fracturing (HF), the location where fractures are initiated is important. To date, most research on fracture initiation has studied the problem in two dimensions. In this study, a three-dimensional model to assess initiation location is developed. The model analyzes the stress state of both the borehole wall and the coal-rock interface and the model shows that the fracture initiation location is affected by in situ stress, the dip of the coal seam, and the angle between the borehole and the coal seam. How the initiation location changes near different types of geological faults is calculated by assuming typical in situ stresses for the faults. Following these calculations, physical experiments were carried out to emulate cross-measure hydraulic fracturing under stress conditions equivalent to those in the Chongqing Tonghua coal mine, China. Fracture initiation during the experiments was monitored by an acoustic emission system. The experimental results were consistent with the theoretical calculations. This implies that the three-dimensional model for assessing the locations of fracture initiation can be applied to forecast the initiation location of fractures generated by cross-measure drilling. The assessment model provides reference values for this type of drilling in underground mines.
\end{abstract}

Keywords: hydraulic fracturing (HF); initiation location; crack propagation; acoustic emissions

\section{Introduction}

At present, to enhance gas drainage efficiency in a low-permeability coal seam, hydraulic fracturing (HF) is used as a standard practice [1-3]. It achieves good results draining coal bed methane in most coal mines. However when using HF, most commonly the focus is on changes in the initiation pressure or fracture extension and the influence of where the fractures are initiated on increasing the seam permeability is neglected [4-7]. In most cases, HF is usually carried out by cross-seam drilling because of the difficulty of in-seam sealing. However, the physical and mechanical differences between the roof, the floor, and the coal seam result in multiple compositional interfaces in the interval being drilled. In addition, coal seams can have two or more layers including soft and hard coal layers as well as rock bands and seams like this are especially common in Southwestern China. The coal-rock mass and its internal interfaces have a significant influence on where fractures are initiated when seams are drilled for HF. The fracture initiation location will have an effect on both the direction in which 
fractures extend and fracture development. Therefore, it is essential to know whether the initiation location is in the coal seam or in the interface when undertaking cross-measure HF drilling. This paper investigates what determines fracture initiation location for drilling across layered coal-rock seams.

Many scholars have studied hydraulic fracture initiation pressure and crack extension direction but the mechanisms controlling the initiation location need further study. Through theoretical analysis, Huang et al. [8,9] found that changes in the inclined shaft angle influenced the crack orientation under the different stress conditions. Feng and Kang [10] analyzed the relationship between azimuth and borehole tilt angle and initiation location for different stress fields. Zhao and Chen [11] studied the extension of hydraulic fractures where the fracture reaches a formation interface. Li et al. [12] proposed a novel stimulation technique to study horizontal well fracturing through interlayers to a coal seam, a study focused on fracture propagation. Li's study, however, was not relevant to cross-measure HF drilling and the relationships between the coal seam and crustal stress were not considered. Zhang et al. [13] studied cross-drilling fracture initiation location theory through plane problem analysis. Zhang et al. [13] hypothesized that (a) initiation location in the axial direction is controlled by the weakest interface, and (b) that initiation location in the radial direction is controlled by minimum tensile strength of the coal and the vertical side stress coefficient.

Currently, most studies on cross-drilling HF fracture initiation have been confined to the two-dimensional problem and have not considered the three-dimensional stress state. Additionally, fracture simulation testing has largely been performed only on coal or on simulated coal material, and the effect of the occurrence of coal interlayered with rock on fracture initiation has not been studied. Due to these two limitations, our knowledge concerning fracture initiation is incomplete and so this paper is aimed at studying the location of cross-drilling HF fracture initiation in coal + rock by comparing the positions of pressure differences. Ranjith et al. [14-16], Lockner [17] think that acoustic emission (AE) technology is an effective tool in the study of rock fracture. It can monitor the internal defect of rock by receipting stress wave. AE technology plays an important role in this paper to monitor the initiation location precisely. The different initiation locations are obtained using a DISP acoustic emission positioning system (PAC Inc., Princeton, NJ, USA).

\section{Fracture Initiation Location}

There are two locations where fractures are initiated when performing cross-measure HF. One is in the coal seam, the other is in the coal-rock interface. There are essential differences between the mechanisms that control fracture initiation at these two locations. The following sections present a mathematical analysis of the two initiation locations. In order to simplify the analysis, in the mathematical model the coal and rock near borehole will be considered to be homogeneous elastic bodies [18-21]. In addition, the filtration effect of the layers and the changes in pore water pressure will not be taken into account in the modeling.

\subsection{Initiation Location in a Coal Seam}

The spatial relationship between a cross-measure HF borehole and a coal seam is shown in Figure 1. Due to the relative orientations of the coal seam and the mine workings, there may be an acute angle between the fracturing borehole and the direction normal to the coal seam ( $\gamma$ in Figure 1). In a vertical section, the relationship between the coal seam dip angle, the angle between the axis of the borehole and the vertical direction, and the angle between the borehole axis and the angle normal to the coal seam is given by Equation (1):

$$
\alpha=\varphi+\gamma \text { or } \alpha=\varphi-\gamma
$$

where $\alpha$ is the angle between the axis of the borehole and vertical direction $\left(^{\circ}\right) ; \varphi$ is the coal seam dip angle $\left({ }^{\circ}\right) ; \gamma$ is the angle between the borehole axis and the angle normal to the coal seam $\left(^{\circ}\right)$. 


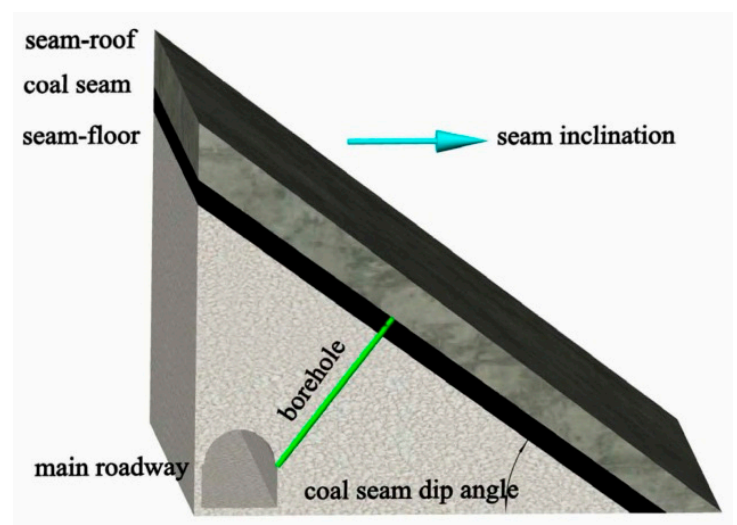

(a)

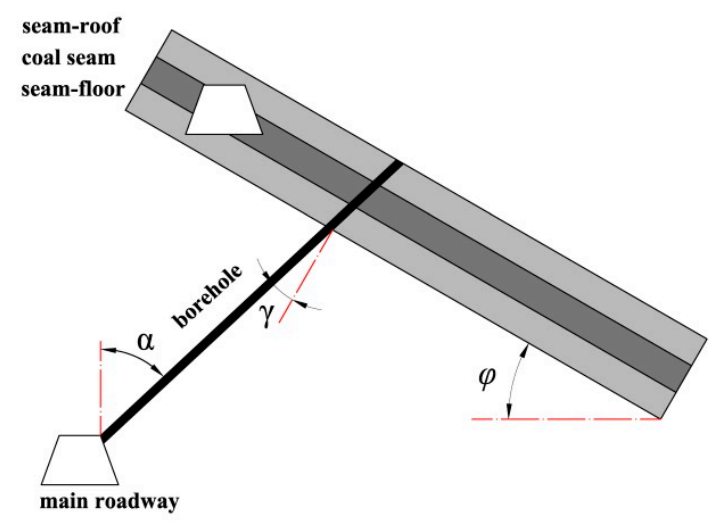

(b)

Figure 1. Diagram showing the relative positions of a hydraulic fracture borehole and a coal seam. (a) Graph showing a 3D view of hydraulic fracture; (b) graph showing a profile view of hydraulic fracture borehole from the seam inclination direction.

When the borehole is perpendicular to the coal seam, $\gamma=0$ and the stress state of the borehole and the coal seam are as is shown in Figure 2. The stress state on the borehole wall can be obtained by converting the Cartesian coordinates of the in situ rock stress [18], as shown in Equation (2):

$$
\left\{\begin{array}{l}
\sigma_{x}=\left(\sigma_{\mathrm{H}} \cos ^{2} \beta+\sigma_{\mathrm{h}} \sin ^{2} \beta\right) \cos ^{2} \alpha+\sigma_{\mathrm{v}} \sin ^{2} \alpha \\
\sigma_{y}=\sigma_{\mathrm{H}} \sin ^{2} \beta+\sigma_{\mathrm{h}} \cos ^{2} \beta \\
\sigma_{z}=\left(\sigma_{\mathrm{H}} \cos ^{2} \beta+\sigma_{\mathrm{h}} \sin ^{2} \beta\right) \sin ^{2} \alpha+\sigma_{\mathrm{v}} \cos ^{2} \alpha \\
\tau_{x y}=\left(\sigma_{\mathrm{h}}-\sigma_{\mathrm{H}}\right) \cos \alpha \cos \beta \sin \beta \\
\tau_{y z}=\left(\sigma_{\mathrm{h}}-\sigma_{\mathrm{H}}\right) \sin \alpha \cos \beta \sin \beta \\
\tau_{z x}=\frac{\left(\sigma_{\mathrm{H}} \cos ^{2} \beta+\sigma_{\mathrm{h}} \sin ^{2} \beta-\sigma_{\mathrm{v}}\right)}{2} \sin 2 \alpha
\end{array}\right.
$$

where $\sigma_{x}, \sigma_{y}, \sigma_{z}, \tau_{x y}, \tau_{y z}$, and $\tau_{z x}$ are the normal and shear stresses in the local coordinate system $(x, y, z) ; \sigma_{\mathrm{v}}$ is the vertical principal stress $(\mathrm{MPa}) ; \sigma_{\mathrm{H}}$ and $\sigma_{\mathrm{h}}$ are the major and minor horizontal principal stresses (MPa); and $\beta$ is the azimuth of the major principle stress $\left(^{\circ}\right)$.

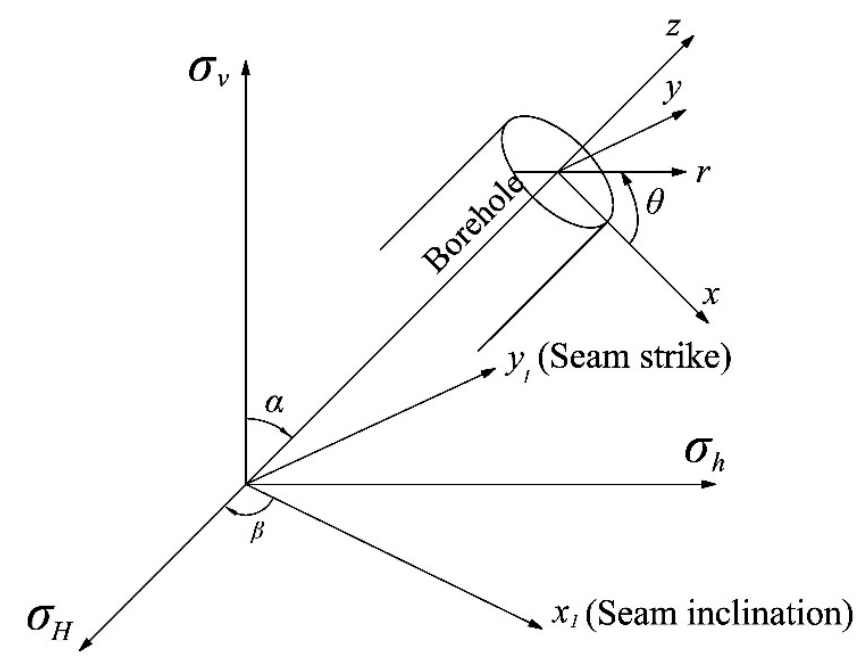

Figure 2. Diagram showing the stress state in a hydraulic fracture borehole wall when the borehole is perpendicular to the coal seam. 
In the cylindrical-coordinate system of the borehole, the stress state of a specific point around the borehole wall can be described by Equation (3):

$$
\left\{\begin{array}{l}
\sigma_{\mathrm{r}}=p \\
\sigma_{\theta}=\left(\sigma_{x}+\sigma_{y}\right)-2\left(\sigma_{x}-\sigma_{y}\right) \cos 2 \theta-4 \tau_{x y} \sin 2 \theta-p \\
\sigma_{z z}=\sigma_{z}-v\left[2\left(\sigma_{x}+\sigma_{y}\right) \cos 2 \theta+4 \tau_{x y} \sin 2 \theta\right] \\
\tau_{\theta z}=2 \tau_{y z} \cos \theta-2 \tau_{x z} \sin \theta \\
\tau_{\mathrm{r} \theta}=\tau_{z \mathrm{r}}=0
\end{array}\right.
$$

where $p$ is the water pressure in the borehole and $\sigma_{\mathrm{r}}, \sigma_{\theta}, \sigma_{z z}, \tau_{\mathrm{r} \theta}, \tau_{\theta z}$, and $\tau_{z \mathrm{r}}$ are the radial, tangential, and axial components of the normal and shear stresses $(\mathrm{MPa})$ at the borehole wall inclined at an angle of $\theta$ with $\sigma_{y}$, respectively.

In general, any point at the borehole wall is considered to be in tensile failure $[19,20]$. Since the tensile strength of coal is less than that of rock, the maximum tangential stress $\sigma_{\theta}$ reaches the tensile strength of coal first. When the stress state satisfies Equation (4), the borehole starts to split. $R_{t}$ is the strength of extension of coal seam.

$$
\left|\begin{array}{l}
\left(\sigma_{x}+\sigma_{y}\right)-2\left(\sigma_{x}-\sigma_{y}\right) \cos 2 \theta \\
-4 \tau_{x y} \sin 2 \theta-p
\end{array}\right| \geqslant R_{t}
$$

Equations (2)-(4) can be combined to obtain Equation (5) to solve for the initiation pressure when the initiation location is in the coal seam $\left(P_{\mathrm{f} 1}\right)$.

$$
P_{\mathrm{f} 1}=\left\{\begin{array}{l}
\left(3 \sigma_{\mathrm{h}}-\sigma_{\mathrm{H}} \cos ^{2} \alpha\right) \cos ^{2} \beta+ \\
\left(3 \sigma_{\mathrm{H}}-\sigma_{\mathrm{h}} \cos ^{2} \alpha\right) \sin ^{2} \beta-\sigma_{\gamma} \sin ^{2} \alpha \\
+4\left(\sigma_{\mathrm{H}}-\sigma_{\mathrm{h}}\right) \cos \alpha \cos \beta \sin \beta \sin 2 \theta+R_{t}
\end{array}\right\}
$$

Substituting Equation (1) into Equation (5) can return the initiation pressure. When the borehole is not completely perpendicular to coal seam, $\gamma \neq 0^{\circ}$.

\subsection{Initiation Location in the Coal-Rock Interface}

According to the interfacial tension failure criterion, the water pressure in the interface must be high enough to overcome the resistance of the interface normal stress and the bonding force, $\mathrm{C}$, for a fracture to form. Resolving the in situ rock stress in the interface normal direction can obtain the initiation pressure in the coal-rock interface, as shown in Equation (6):

$$
P_{\mathrm{f} 2}=\sigma_{\mathrm{H}} \sin \alpha \cos \beta+\sigma_{\mathrm{h}} \sin \beta \cos \alpha+\sigma_{\nu} \sin \alpha+C
$$

where $P_{\mathrm{f} 2}$ is the initiation pressure in the coal-rock interface and $C$ is the bonding force.

\subsection{Model to Determine the Initiation Location}

The initiation location, $F$, will be where the initiation pressure in the coal seam or the coal-rock interface is lowest. To compare the values of the two initiation pressures, determine $F=P_{\mathrm{f} 1}-P_{\mathrm{f} 2}$. This allows Equation (7) to be written as:

$$
\begin{aligned}
& F=\left(3 \sigma_{h}-\sigma_{H} \cos ^{2} \alpha\right) \cos ^{2} \beta+\left(3 \sigma_{H}-\sigma_{h} \cos ^{2} \alpha\right) \sin ^{2} \beta \\
& -\sigma_{\gamma} \sin ^{2} \alpha+4\left(\sigma_{H}-\sigma_{h}\right) \cos \alpha \cos \beta \sin \beta \sin 2 \theta \\
& -\left(\sigma_{H} \sin \alpha \cos \beta+\sigma_{h} \sin \beta \cos \alpha+\sigma_{\nu} \sin \alpha\right)+R_{t}-C
\end{aligned}
$$

Equation (7) shows that $F$ is a function of the in-situ rock stresses $\left(\sigma_{\mathrm{H}}, \sigma_{\mathrm{h}}, \sigma_{\mathrm{v}}\right)$, the angle between the axis of borehole and the vertical, and the azimuth of the major principle stress. The ranges for the 
values of the parameters are: $\alpha \in(0, \pi / 2), \beta \in(0, \pi)$ and $\theta \in(0,2 \pi)$. Since $\theta$ is changing, $F$ still has a minimum value $F_{\min }$ when the other parameters are defined.

When $F_{\min }<0, P_{\mathrm{f} 1}<P_{\mathrm{f} 2}$ meaning the initiation location is in the coal seam.

When $F_{\min }>0, P_{\mathrm{f} 1}>P_{\mathrm{f} 2}$ meaning the initiation location is in the coal-rock interface.

\section{Analysis of Initiation Location Parameters}

Generally, in situ rock stress is a combination of stress from the overlying strata due to gravity and tectonic stresses. The vertical principal stress is in almost all cases relatively constant. However, the horizontal maximum and minimum stresses show great variability near different kinds of faults. Normal faults, reverse faults, and strike-slip faults have different principle stress states, as shown in Figure 3.
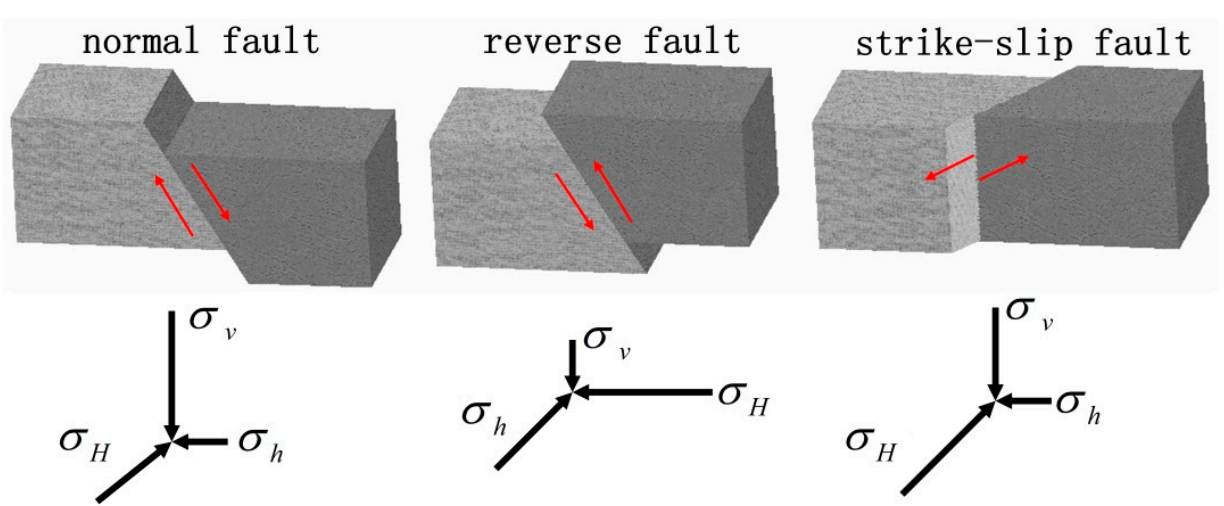

Figure 3. Schematic block diagrams showing the principle stress states of normal, reverse, and strike-slip faults. $\sigma_{\mathrm{H}}$ and $\sigma_{\mathrm{h}}$ are the major and minor horizontal principal stresses, $\sigma_{\mathrm{v}}$ is the vertical principal stress.

Equation (7) shows that the initiation location of cross-measure HF is determined by multiple parameters. In order to analyze the main parameters affecting the initiation location, we neglect the minor factors and make the following assumptions:

1. Since the strength of extension of coal and the coal bonding force are constant and they both inhibit the initiation pressure, it is assumed that their values are equal;

2. The borehole is perpendicular to coal seam;

3. The coal seam depth of burial is $500 \mathrm{~m}$. The ratios of the principle stresses of a normal fault are $\sigma_{\mathrm{v}}: \sigma_{\mathrm{H}}: \sigma_{\mathrm{h}}=3: 2: 1$, those for a reverse fault are $\sigma_{\mathrm{v}}: \sigma_{\mathrm{H}}: \sigma_{\mathrm{h}}=1: 3: 2$, and stress ratios for a strike-slip fault are $\sigma_{\mathrm{v}}: \sigma_{\mathrm{H}}: \sigma_{\mathrm{h}}=2: 3: 1$.

According to the statistics on the stress state in the shallow crust in China reported by Jing $e$ et al. [22], the three principle stresses conform to the rules shown in Equation (8). Based on the assumptions above, the variation of $F_{\min }$ can be computed using MATLAB R2013a software (MathWorks Inc., Natick, MA, USA), for $\alpha=0^{\circ}, 30^{\circ}, 45^{\circ}, 60^{\circ}$, and $90^{\circ}$ and $\beta=0^{\circ}, 45^{\circ}, 90^{\circ}, 135^{\circ}$, and $180^{\circ}$.

$$
\left\{\begin{array}{l}
\sigma_{\mathrm{v}}=0.027 H \\
0.6 \leqslant \frac{\sigma_{H}}{\sigma_{\mathrm{v}}} \leqslant \frac{1550}{H}+0.6 \\
0.35 \leqslant \frac{\sigma_{\mathrm{h}}}{\sigma_{\mathrm{v}}} \leqslant \frac{810}{H}+0.6
\end{array}\right.
$$

The calculated variations for $F_{\min }$ with different $\alpha^{\prime}$ s and $\beta$ 's is as shown in Figure 4. 


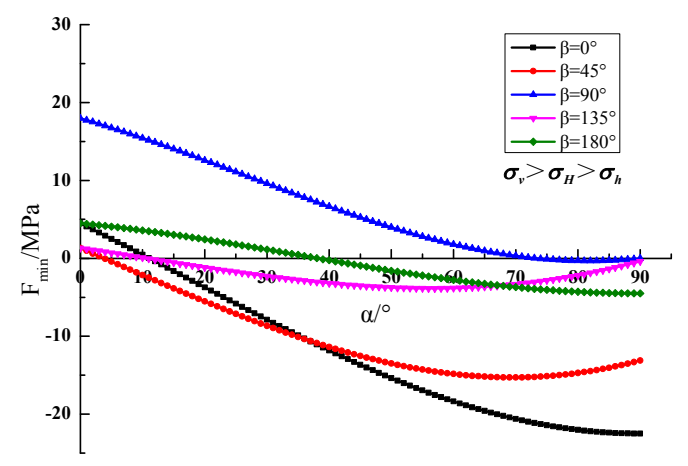

(a)

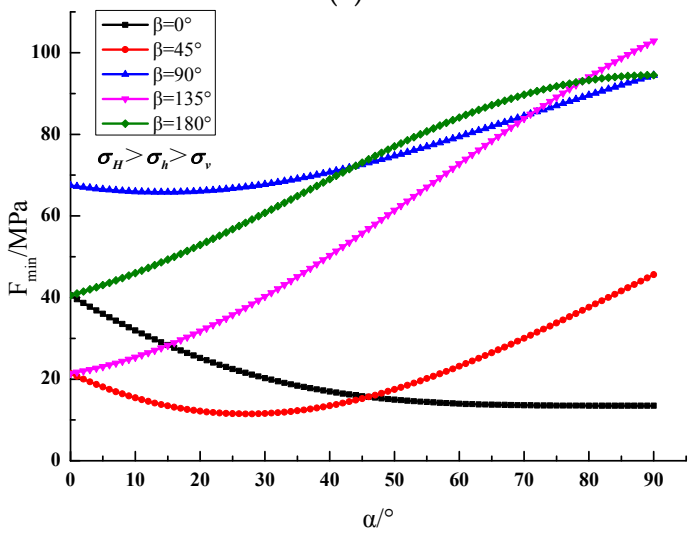

(c)

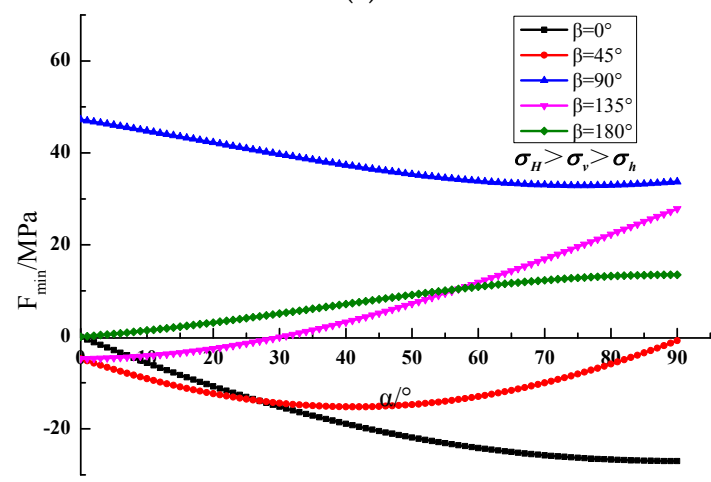

(e)

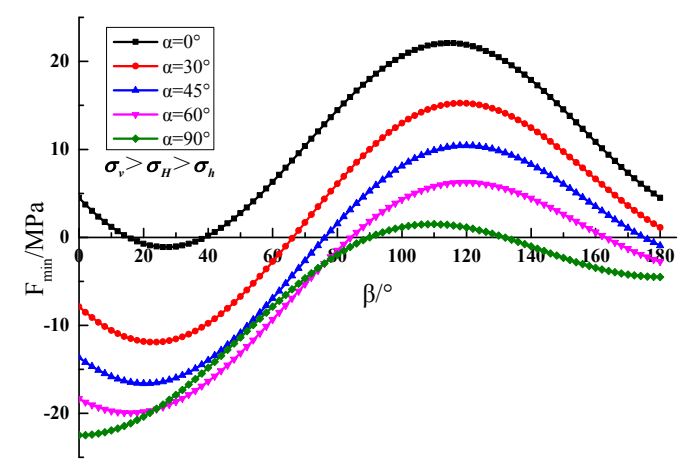

(b)

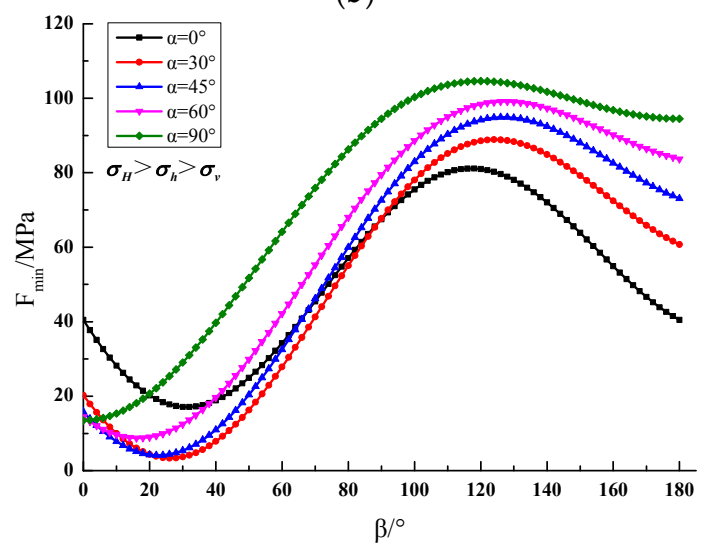

(d)



(f)

Figure 4. Graph showing $F_{\min }$ variation in three different faults. (a) Graph showing $F_{\min }$ variation with $\alpha$ in a normal fault; (b) graph showing $F_{\min }$ variation with $\beta$ in a normal fault; (c) graph showing $F_{\min }$ variation with $\alpha$ in a reverse fault; (d) graph showing $F_{\min }$ variation with $\beta$ in a reverse fault; (e) graph showing $F_{\min }$ variation with $\alpha$ in a strike-slip fault; and (f) graph showing $F_{\min }$ variation with $\beta$ in a strike-slip fault.

Considering the physical meaning of $F_{\min }$, Figure 4 a shows that with the angle between the borehole axis and the vertical increasing near a normal fault, $F_{\min }$ mainly decreases. This means that the initiation location tends to be in the coal-rock interface. Figure $4 \mathrm{c}$ shows that $F_{\text {min }}$ mainly increases near reverse faults, therefore the initiation location tends to be in the coal seam. Figure 4e shows that $F_{\min }$ does not have a specific variation tendency near strike-slip faults, therefore the initiation location is determined by the value of $\alpha$ for that particular drill hole.

Figure $4 \mathrm{~b}, \mathrm{~d}, \mathrm{f}$ shows that with $\beta$ increasing, $F_{\min }$ changes in a similar fashion for the three types of faults. The values of $F_{\min }$ follow a "valley-peak-valley" pattern. This pattern shows that the initiation location conforms to a similar pattern; "initiation location in coal seam-initiation location in coal-rock interface-initiation location in coal seam" as the direction of the principal stress changes. 
Although the analysis above is an example of one analysis based on calculations performed under specific conditions, the variations in $F_{\min }$ demonstrated can provide a reference for applying the assessment criteria. The actual initiation location in any specific location should be computed by using the parameters at that locality.

\section{Physical Simulation Experiments}

\subsection{Test System}

In order to verify the validity of the initiation location determination criteria for different coal seams, we conducted some tests in the laboratory. These tests were similar to typical HF tests for coal seams. The purpose of the tests was to obtain the relationship between the actual crack pressure and the initiation location of the crack in relation to the dip of the coal seam. The tests used a three-axis HF simulation test system made up of four main parts: the pump system, the pressure flow system, stress loading system, and DISP acoustic emission test system. The pump system uses a $31.5 \mathrm{~L} / \mathrm{min}$, $20 \mathrm{MPa}$ high-pressure water pump, the pressure flow measurement system is composed of a $500 \mathrm{kN}$ electrohydraulic servo three axis test machine, an electromagnetic flowmeter, and a signal receiving apparatus, and the stress loading system uses self-designed hydraulic pressure loading devices. System connections are shown in Figure 5.

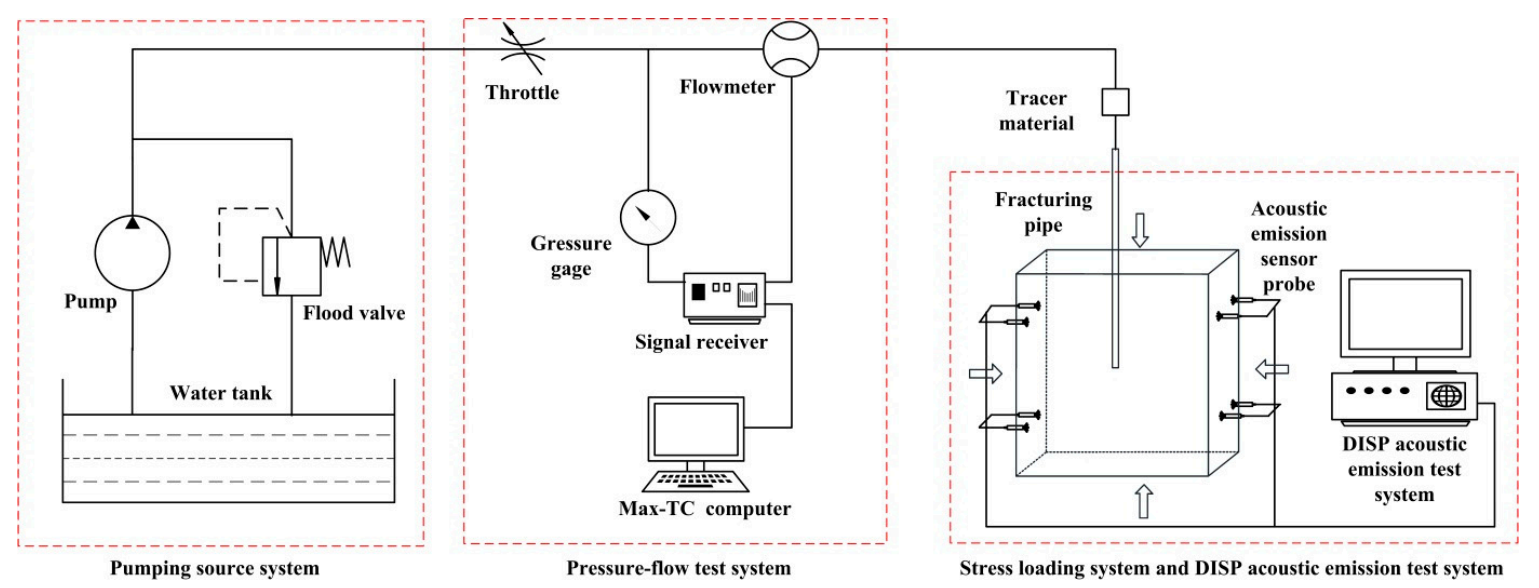

Figure 5. Schematic diagram showing the hydraulic fracturing (HF) test system.

\subsection{Sample Preparation and Stress Loading}

Test samples were manufactured to resemble coal and rock from the Tonghua coal mine in the Songzao Mining Area, Chongqing, China. In order to decide on the appropriate mix of constituents for the samples, six sets of preliminary samples were prepared to compare their compressive strength to that of samples collected in the field [23,24]. The test samples, $7 \mathrm{~cm}$ cubes as shown in Figure 6, were prepared according to Chinese national standards in procedures for "Method for determining the physical and mechanical properties of coal and rock" (GB/T23561.1-2009) and "Standard for test method of basic properties of construction mortar" (JGJ/T70-2009). Strength tests were performed using an AG-I electronic precision material testing machine. Based on the results of those tests, a ratio of cement: river sand of 1:6.38 was chosen for the simulated rock material and a coal: cement: gypsum ratio of 3:1:1 was deemed most appropriate for the simulated coal material. The test results are shown in Table 1. 


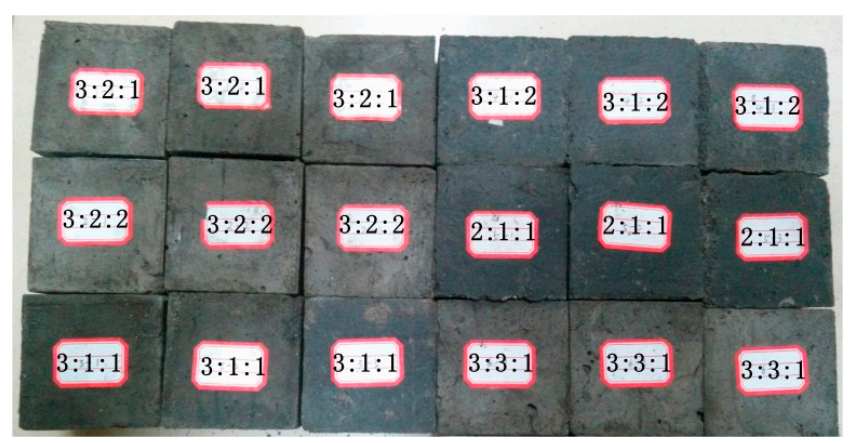

Figure 6. Photograph of $7 \mathrm{~cm}$ cubes of coal seam simulation material. The numbers on the cubes represent the different coal: cement; gypsum ratios used to manufacture the test cubes.

Table 1. Basic mechanical parameters of the samples used in the HF tests.

\begin{tabular}{ccccc}
\hline Material & Material Ratio & $\begin{array}{c}\text { Compressive Strength } \\
\mathbf{( M P a )}\end{array}$ & $\begin{array}{c}\text { Strength of Extension } \\
\mathbf{( M P a )}\end{array}$ & $\begin{array}{c}\text { Unit Weight } \\
\left(\mathbf{g} / \mathbf{c m}^{3} \mathbf{)}\right.\end{array}$ \\
\hline Rock strata & $\begin{array}{c}\text { cement:sand }=1: 6.38 \\
\text { Coal seam }\end{array}$ & 6.81 & 0.47 & 2.13 \\
& coal:cement:gypsum = 3:1:1 & 3.62 & 0.23 & 1.92 \\
\hline
\end{tabular}

The specimens are made in a $300 \mathrm{~mm} \times 300 \mathrm{~mm} \times 300 \mathrm{~mm}$ die. By changing the height of the four pivot points of the die to control the coal rock strata. After mixing the material with water, it is placed in the die in order by layer using a steel rule to measure and control the thickness of the coal seam. The fracturing pipe to connect with hydraulic line is set into the specimen and $110 \mathrm{~mm}$ long by $3 \mathrm{~mm}$ diameter hole simulation fractures are drilled at the lower end of the fracturing pipe. It is very important to cement the samples at the interface during the test. In order to avoid the presence of strength defects in the coal-rock interface, the die should be shaken many times to prevent natural fractures existing in the coal-rock interface. Natural fractures in the coal seam would influence the initiation location of the crack. After the specimen is made, the relationship between the fracture tube and the stress loading position cannot be changed $\left(\alpha=0^{\circ}\right)$. All samples were made with $\varphi=20^{\circ}$ and $\beta=0^{\circ}, 30^{\circ}, 45^{\circ}, 60^{\circ}, 90^{\circ}$, as shown in Figure 7 .

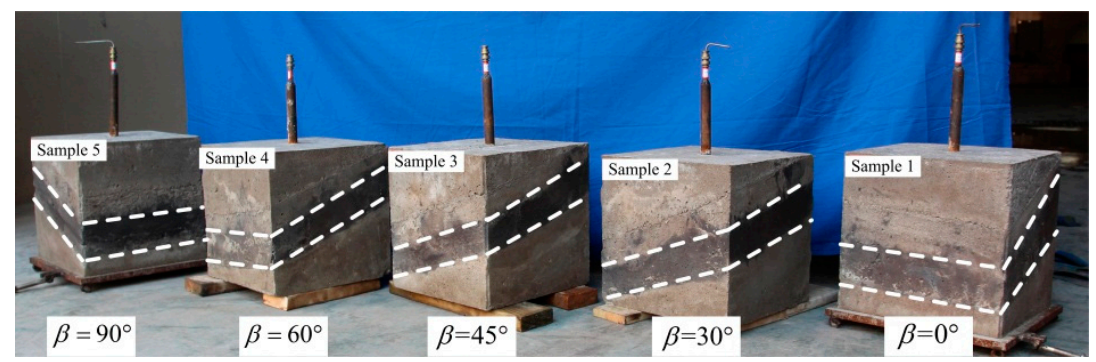

Figure 7. Photograph of five specimens used for hydraulic fracture testing. The specimens are $300 \mathrm{~mm}$ cubes and each has a fracturing pipe protruding from the top. The specimens were all made with the simulated coal seam dipping at $20^{\circ}$ but each specimen was tested under a different principal stress (the " $\beta=x$ " number shown for each specimen).

When HF is carried out, preexisting stresses play a major role in the initiation and expansion of cracks. Therefore, setting the stress environment to match those that would exist in the natural environment is very important for the tests. We use the in situ stress measurement result in Tonghua coal mine to simulate stresses, as shown in Table 2 [25]. The sample is under triaxial simulate stresses to match the in situ stresses. The three directions of the sample all have a surface under displacement constraints, and the opposite surface is under stresses constraints, as shown in Figure 8. 


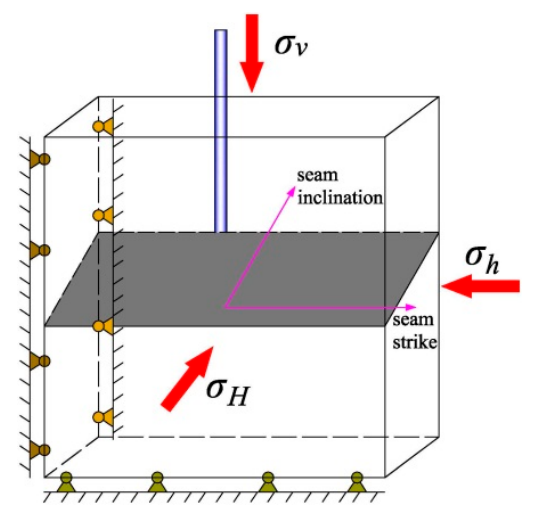

Figure 8. Schematic diagram showing the sample confinement (take $\beta=0^{\circ}$ sample for example).

Table 2. Test result of in-situ stress in Tonghua coalmine [25].

\begin{tabular}{cccc}
\hline Category & $\sigma_{\mathbf{H}}$ & $\sigma_{\mathbf{h}}$ & $\sigma_{\mathbf{v}}$ \\
\hline Principle stress/MPa & 23.7 & 9.9 & 4.5 \\
$\theta_{x}$ (The angle between principal stress and $\mathrm{x}$ ) $/^{\circ}$ & 39.0 & 94.6 & 51.1 \\
$\theta_{y}$ (The angle between principal stress and y) ${ }^{\circ}$ & 129.1 & 87.8 & 38.9 \\
$\theta_{z}$ (The angle between principal stress and z) $/^{\circ}$ & 86.8 & 3.4 & 88.4 \\
\hline
\end{tabular}

According to reference [23], the tests are in general similar to the geometry, the unit weight, the strength of extension and the stress field that would be present in a real-world HF situation. Comparing the test specimens and test conditions with those that might pertain in a working coal mine, the simulated coal seam thickness: real coal seam thickness ratio is 1:10, the bulk density similarity ratio is $1.22: 1$, the strength of extension similarity ratio is $0.79: 1$, and the experimental stress: the actual site stress ratio is 1:10. Therefore, the triaxial simulate stresses are $2.37 \mathrm{MPa}$ (the major horizontal principal stresses), $0.99 \mathrm{MPa}$ (the minor horizontal principal stresses), $0.45 \mathrm{MPa}$ (the vertical principal stresses).

\section{Results and Discussion}

\subsection{Sensor Arrangement and Acoustic Emission (AE) Sensor Verification}

In order to monitor the initiation location and fracture shape during the HF experiments, eight DISP acoustic emission (AE) sensors were attached on the outside of the specimen along the coal seam [26]. Two sides of the specimen had four sensors each, and the sensors were placed $5 \mathrm{~cm}$ away from the edges, as shown in Figure 9a. To verify that the sensors were recording the correct location of the fractures, a tracer was introduced into the fracturing fluid so that the tracer material would attach itself to the fracture surface when the fracturing fluid entered the cracks. The goal was to see whether the AE events faithfully represented the fracture initiation locations and fracture shape. After this experiment, we cut the specimen apart to expose the tracer-coated fracture surface. As shown in Figure $9 b$, the AE-recorded fracture sites agree well with the sites impregnated with tracer material site, verifying the validity of the $\mathrm{AE}$ events. 


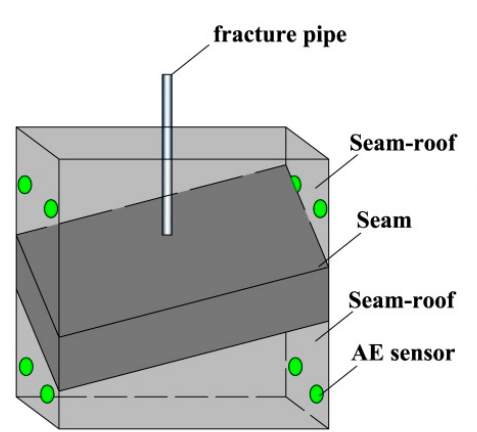

(a)

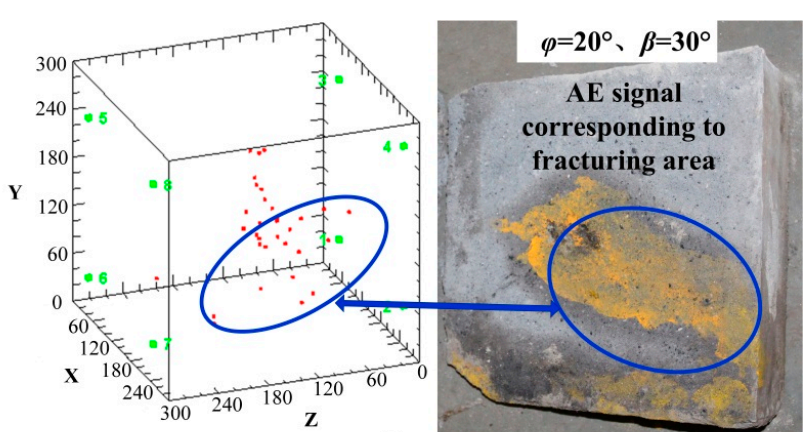

(b)

Figure 9. Location of acoustic emission (AE) sensors on the HF test sample (a) and block diagrams (b) showing AE-recorded event sites and a photograph of a fracture surface in the tested specimen. A tracer was introduced into the fracturing fluid and the presence of the tracer material (light brown in the photograph) on the fracture surface verifies that the $\mathrm{AE}$ events recorded the fracture initiation sites and fracture shape well.

\subsection{Fracture Initiation Location Verification}

The mathematical model is aimed at forecasting the fracture initiation location during cross-measure drilling for HF, and the article verifies the model through comparing the initiation location of the experiment with the forecast result of the mathematical model. To verify the validity of the mathematical model, there are four steps of the initiation location verification.

Firstly, we can obtain the variation of $F_{\min }$ by substituting every parameter into the mathematical model, as shown in Equation (7). The tensile strength of the simulated coal seam material is just $0.23 \mathrm{MPa}$ and the bonding force of coal-rock interface cannot be simulated quantitatively. However, because these two values have less effect than the other parameters on where fractures initiate, it is assumed that these values are equal for the purpose of verifying the initiation location model. Calculation results show that $F_{\min }$ is negative when $\beta$ is between $7^{\circ}$ and $41^{\circ}$, which means that for those values of $\beta$, fractures will initiate in the coal seam. Conversely, $F_{\min }$ is positive when $\beta$ is less than $7^{\circ}$ or greater than $41^{\circ}$, which means fracture initiation will be in the coal-rock interface. Therefore, the initiation location variation with $\beta$ can be described as shown in Figure 10.

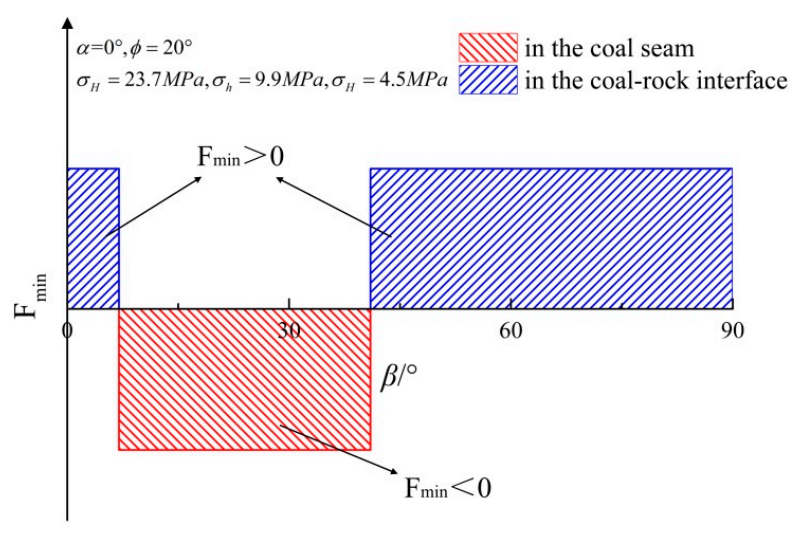

Figure 10. Graph showing the variation in theoretical fracture initiation location. For values of $\beta$ between $7^{\circ}$ and $41^{\circ}, F_{\min }$ is negative and fractures will initiate in the coal seam. For all other values of $\beta, F_{\min }$ is positive and fractures initiate in the coal-rock interface.

Secondly, the initiation location of sample can be monitored by the DISP AE system during the experiment. The experiment just described shows that the initiation locations and the shape of the fracture can be estimated by the sequence of AE events. Figure 11 shows the AE events in two samples 
with different values for $\beta$. The sample in Figure 11a has $\varphi=20^{\circ}, \beta=30^{\circ}$ and the fractures initiate in the coal seam whereas the sample in Figure $11 \mathrm{~b}$ has $\varphi=20^{\circ}, \beta=90^{\circ}$ and the fractures initiate in the coal-rock interface.
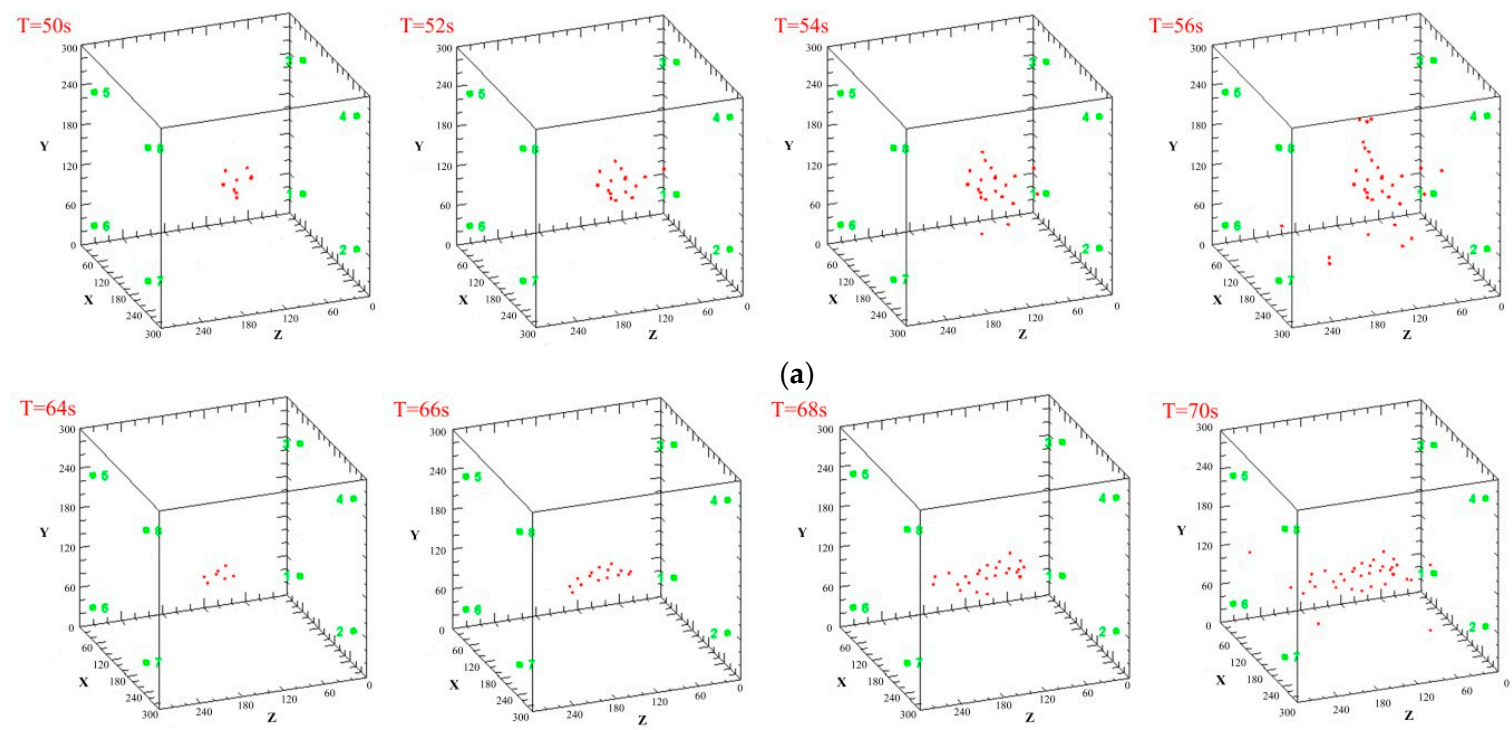

(a)
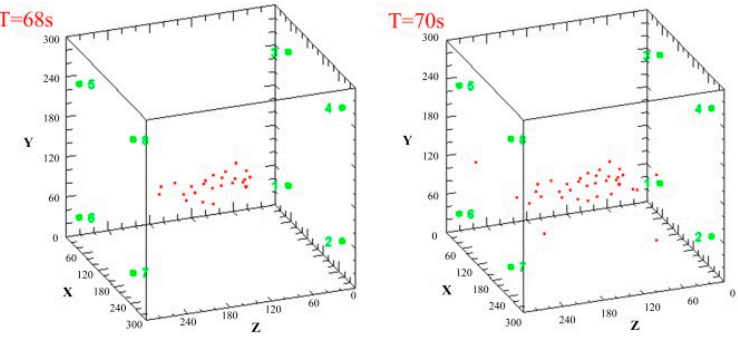

(b)

Figure 11. Block diagrams showing acoustic emission event time sequences. The block diagrams in (a) represent time progressions during the experimental run from $T=50 \mathrm{~s}$ on the left to $T=56 \mathrm{~s}$ on the right and (b) from $T=64 \mathrm{~s}$ on the left to $T=70 \mathrm{~s}$ on the right. Figure 11a shows events for a samples with $\varphi=20^{\circ}, \beta=30^{\circ}$, and the locations of the $\mathrm{AE}$ events indicate that the fractures initiated in the coal seam. Figure $11 \mathrm{~b}$ shows a sample with $\varphi=20^{\circ}, \beta=90^{\circ}$, and for this sample the fractures initiated in the coal-rock interface. The green numbered dots are the locations of the AE sensors.

Thirdly, the tracer material in the samples can be observed for judging the initiation location. The initiation location conditions for the five types of samples are shown in Table 3. The experiment results show that initiation location is in the coal seam only when $\alpha=0^{\circ}$ and $\beta=30^{\circ}$ (Sample 2), indicating that $F_{\min }$ is negative, whereas the initiation location is in the coal-rock interface when $\alpha=0^{\circ}$ and $\beta=0^{\circ}, 45^{\circ}, 60^{\circ}, 90^{\circ}$ (Sample $1,3,4,5$ ) indicating that $F_{\min }$ is positive.

Table 3. Monitor results for initiation locations.

\begin{tabular}{|c|c|c|c|c|c|}
\hline $\begin{array}{l}\text { Sample } \\
\text { condition }\end{array}$ & $\begin{array}{c}\alpha=0^{\circ}, \beta=0^{\circ} \\
\varphi=20^{\circ}\end{array}$ & $\begin{array}{c}\alpha=0^{\circ}, \beta=30^{\circ}, \\
\varphi=20^{\circ}\end{array}$ & $\begin{array}{c}\alpha=0^{\circ}, \beta=45^{\circ} \\
\varphi=20^{\circ}\end{array}$ & $\begin{array}{c}\alpha=0^{\circ}, \beta=60^{\circ} \\
\varphi=20^{\circ}\end{array}$ & $\begin{array}{c}\alpha=0^{\circ}, \beta=90^{\circ} \\
\varphi=20^{\circ}\end{array}$ \\
\hline$F_{\min }$ & $F_{\min }>0$ & $\boldsymbol{F}_{\min }<0$ & $\boldsymbol{F}_{\min }>0$ & $\boldsymbol{F}_{\min }>0$ & $F_{\min }>0$ \\
\hline $\begin{array}{l}\text { Monitor } \\
\text { initiation } \\
\text { location }\end{array}$ & $\begin{array}{c}\text { in coal-rock } \\
\text { interface }\end{array}$ & in coal seam & $\begin{array}{l}\text { in coal-rock } \\
\text { interface }\end{array}$ & $\begin{array}{c}\text { in coal-rock } \\
\text { interface }\end{array}$ & $\begin{array}{c}\text { in coal-rock } \\
\text { interface }\end{array}$ \\
\hline Fracture shape & & & & & \\
\hline
\end{tabular}

Finally, by comparing the monitor initiation location, the observed initiation location with the variation in mathematical model, we can verify the validity of the mathematical model. Table 3 shows that the experimental results correspond with the theoretical calculations, indicating that the three-dimensional initiation location model for cross-measure HF can be applied in engineering. 
According to the experiments, the crack will extend along the interface forming a single main fracture plane when the initiation location is in the coal-rock interface. Additionally, the crack will preferentially propagate in the coal seam before crossing the coal-rock interface when the initiation location is in coal seam. Subsequently, the crack will turn into the interface when it intersects the coal-rock interface. Variations in the initiation location will affect the propagation of cracks in subsequent HF efforts. The more cracks propagate in the coal seam, the more the coal seam permeability can be increased. Obviously, cracks splitting and propagating in the coal seam improve seam permeability more than a single fracture plane along the interface.

These days, the use of high technology hydraulic power measures to improve the permeability of coal seams is increasing; techniques such as guiding-drilling pressure relief and HF combined with slotting technology $[21,27]$. The purpose of these measures is to generate more cracks propagating in coal seams and improve the gas extraction after fracturing. This is a new trend using pluralistic research methods to reduce coal and gas outburst disasters.

\section{Conclusions}

(1) In this study, a three-dimensional model for assessing fracture initiation locations when drilling cross-measure hydraulic fracture boreholes is developed by analyzing the stress state of the borehole and the coal-rock interface. The model shows that the initiation location is co-determined mainly by in situ stress, coal seam dip angle, the angle between the axis of the borehole and vertical, and the angle between the axis of the borehole and the direction normal to the coal seam.

(2) Fracture initiation parameters are analyzed for three faults using some assumptions. As the angle between the borehole axis and the vertical direction increases, the fracture initiation location tends to be in the coal seam in normal fault areas, whereas it tends to be in the coal-rock interface in reverse fault areas. The initiation location does not show a preferred variation tendency near strike-slip faults where variation in the initiation location is determined by local conditions. However, as the azimuth of the major principle stress increases, the initiation location has the same variation tendency in all three types of faults. This behavior entirely conforms to the tendency of "in coal seam-in coal-rock interface-in coal seam" predicted by the mathematical model.

(3) A physical simulation experiment was carried out to study cross-measure drilling fracture initiation locations using stress conditions identical to those present in the Chongqing Tonghua coal mine. The result of those simulation experiments verify the validity of the assessment model and, thus, provides a reference for underground coal mine HF engineering.

Acknowledgments: This study was financially supproted by the National Natural Science Foundation of China (NSFC) under Contract No. 51374258, the National Natural Science Foundation of China (NSFC) under Contract No. 51504046 and Changjiang Scholars and Innovative Research Team in University under Contract No. IRT13043.

Author Contributions: Yiyu Lu and Zhaolong Ge conceived and designed the experiments; Liang Cheng, Shaojie Zuo and Jianyu Zhong performed the experiments; Yugang Cheng analyzed the data and wrote the paper.

Conflicts of Interest: The authors declare no conflict of interest.

\section{References}

1. Li, L.C.; Xia, Y.J.; Huang, B.; Zhang, L.Y.; Li, M.; Li, A.S. The Behaviour of Fracture Growth in Sedimentary Rocks: A Numerical Study Based on Hydraulic Fracturing Processes. Energies 2016, 9. [CrossRef]

2. Zhai, C.; Yu, X.; Xiang, X.W.; Li, Q.G.; Wu, S.L.; Xu, J.Z. Experimental study of pulsating water pressure propagation in CBM reservoirs during pulse hydraulic fracturing. J. Nat. Gas Sci. Eng. 2015, 25, 15-22. [CrossRef]

3. Zhang, Z.B.; Li, X.; Yuan, W.N.; He, J.M.; Li, G.F.; Wu, Y.S. Numerical analysis on the optimization of hydraulic fracture networks. Energies 2015, 8, 12061-12079. [CrossRef]

4. Wang, W.C.; Li, X.Z.; Lin, B.Q.; Zhai, C. Pulsating hydraulic fracturing technology in low permeability coal seams. Int. J. Min. Sci. Technol. 2015, 25, 681-685. [CrossRef] 
5. Wang, T.; Zhou, W.B.; Chen, J.H.; Xiao, X.; Li, Y.; Zhao, X.Y. Simulation of hydraulic fracturing using particle flow method and application in a coal mine. Int. J. Coal Geol. 2014, 121, 1-13. [CrossRef]

6. Tang, S.H.; Zhu, B.C.; Yan, Z.F. Effect of crustal stress on hydraulic fracturing in coalbed methane wells. J. China Coal Soc. 2011, 36, 65-69. (In Chinese)

7. Yang, J.S.; Wang, Y.B.; Li, A.Q.; Chen, Z.H.; Chen, Y.P.; Zou, Y.S. Experimental study on propagation mechanism of complex hydraulic fracture in coal-bed. J. China Coal Soc. 2012, 37, 73-77. (In Chinese)

8. Huang, J.; Griffiths, D.V.; Wong, S.W. In situ stress determination from inversion of hydraulic fracture data. Int. J. Rock Mech. Min. 2011, 48, 476-481. [CrossRef]

9. Huang, J.; Griffiths, D.V.; Wong, S.W. Initiation pressure, location and orientation of hydraulic fracture. Int. J. Rock Mech. Min. 2012, 49, 59-67. [CrossRef]

10. Feng, Y.J.; Kang, H.P. Hydraulic fracturing initiation and propagation. Chin. J. Rock Mech. Eng. 2013, 32, 3169-3179. (In Chinese)

11. Zhao, H.F.; Chen, M. Extending behavior of hydraulic fracture when reaching formation interface. J. Petrol. Sci. Eng. 2010, 71, 26-30. [CrossRef]

12. Li, D.Q.; Zhang, S.C.; Zhang, S.A. Experimental and numerical simulation study on fracturing through interlayer to coal seam. J. Nat. Gas Sci. Eng. 2014, 21, 386-396. [CrossRef]

13. Zhang, G.H.; Wei, G.P.; Hou, F.C. Theory of start-split affusion stress and start-split location about through coal delam inaions' bore of hydraulic fracture. J. China Coal Soc. 2007, 32, 52-55. (In Chinese)

14. Ranjith, P.G.; Jasinge, D.; Choi, S.K.; Mehic, M.; Shannon, B. The effect of $\mathrm{CO}_{2}$ saturation on mechanical properties of Australian black coal using acoustic emission. Fuel 2010, 89, 2110-2117. [CrossRef]

15. Perera, M.S.A.; Ranjith, P.G.; Viete, D.R. Effects of gaseous and super-critical carbon dioxide saturation on the mechanical properties of bituminous coal from the Southern Sydney Basin. Appl. Energy 2013, 110, 73-81. [CrossRef]

16. Perera, M.S.A.; Ranjith, P.G.; Peter, M. Effects of saturation medium and pressure on strength parameters of Latrobe Valley brown coal: Carbon dioxide, water and nitrogen saturations. Energy 2011, 36, 6941-6947. [CrossRef]

17. Lockner, D. The role of acoustic emission in the study of rock fracture. Int. J. Rock Mech. Min. 1993, 30, 883-899. [CrossRef]

18. Chen, M.; Jin, Y.; Zhang, G.Q. Rock Mechanics of Petroleum Engineering; Science Press: Beijing, China, 2008; pp. 167-173.

19. Hossain, M.M.; Rahman, M.K.; Rahman, S.S. Hydraulic fracture initiation and propagation: Roles of wellbore trajectory, perforation and stress regimes. J. Petrol. Sci. Eng. 2000, 27, 129-149. [CrossRef]

20. Li, C.L.; Kong, X.Y. A theoretical study on rocks break down pressure calculation equation of fracturing process. Oil Drill. Prod. Technol. 2000, 22, 54-57.

21. Liu, Y.; Xia, B.W.; Liu, X.T. A novel method of orienting hydraulic fractures in coal mines and its mechanism of intensified conduction. J. Nat. Gas Sci. Eng. 2015, 27, 190-199. [CrossRef]

22. Jing, F.; Sheng, Q.; Zhang, Y.H.; Luo, C.W.; Liu, Y.K. Research on distribution rule of shallow crustal geostress in China mainland. Chin. J. Rock Mech. Eng. 2007, 26, 2056-2062. (In Chinese)

23. Li, X.H.; Lu, Y.Y.; Kang, Y.; Rao, B.H. Rock Mechanics Experiment Simulation Technology; Science Press: Beijing, China, 2007; pp. 25-44.

24. Lin, H.X.; Du, C.Z. Experimental research on the quasi three-axis hydraulic fracturing of coal. J. China Coal Soc. 2011, 36, 1801-1805. (In Chinese)

25. Lu, Y.Y.; Cheng, L.; Ge, Z.L.; Xia, B.W.; Li, Q.; Chen, J.F. Analysis on the initial cracking parameters of cross-measure hydraulic fracture in underground coal mines. Energies 2015, 8, 6977-6994. [CrossRef]

26. Eleni, T.; Dimitrios, G.A.; Theodore, E.M.; Anastasios, C.M. Acoustic emission activity for characterizing fracture of marble under bending. Appl. Sci. 2016, 6. [CrossRef]

27. Yan, F.Z.; Lin, B.Q.; Zhu, C.J.; Shen, C.M.; Zou, Q.L.; Guo, C.; Liu, T. A novel ECBM extraction technology based on the integration of hydraulic slotting and hydraulic fracturing. J. Nat. Gas Sci. Eng. 2015, 22, 571-579. [CrossRef]

(C) 2016 by the authors; licensee MDPI, Basel, Switzerland. This article is an open access article distributed under the terms and conditions of the Creative Commons Attribution (CC-BY) license (http://creativecommons.org/licenses/by/4.0/). 